CrossMark Click for updates
Cross

Cite this: J. Mater. Chem. B, 2017, 5, 517

Received 20th September 2016, Accepted 6th December 2016

DOI: $10.1039 / c 6 t b 02441 f$

www.rsc.org/MaterialsB

\section{Bioactive peptide functionalized aligned cyclodextrin nanofibers for neurite outgrowth $\dagger$}

\author{
Seren Hamsici, Goksu Cinar, Asli Celebioglu, Tamer Uyar, * Ayse B. Tekinay* and \\ Mustafa O. Guler*
}

\begin{abstract}
Guidance of neurite extension and establishment of neural connectivity hold great importance for neural tissue regeneration and neural conduit implants. Although bioactive-epitope functionalized synthetic or natural polymeric materials have been proposed for the induction of neural regeneration, chemical modifications of these materials for neural differentiation still remain a challenge due to the harsh conditions of chemical reactions, along with non-homogeneous surface modifications. In this study, a facile noncovalent functionalization method is proposed by exploiting host-guest interactions between an adamantane-conjugated laminin derived bioactive IKVAV epitope and electrospun cyclodextrin nanofibers (CDNFs) to fabricate implantable scaffolds for peripheral nerve regeneration. While electrospun CDNFs introduce a three-dimensional biocompatible microenvironment to promote cellular viability and adhesion, the bioactive epitopes presented on the surface of electrospun CDNFs guide the cellular differentiation of PC-12 cells. In addition to materials synthesis and smart functionalization, physical alignment of the electrospun nanofibers guides the cells for enhanced differentiation. Cells cultured on aligned and IKVAV functionalized electrospun CDNFs had significantly higher expression of neuron-specific $\beta I I I$-tubulin and synaptophysin. The neurite extension is also higher on the bioactive aligned scaffolds compared to random and non-functionalized electrospun CDNFs. Both chemical and physical cues were utilized for an effective neuronal differentiation process.
\end{abstract}

\section{Introduction}

Neurotraumas including spinal cord and peripheral nerve injuries are significant health problems across the world and cause severe disabilities with more than 100000 new injuries each year. ${ }^{1}$ Nerve autografts constitute the gold standard for the treatment of peripheral nerve injuries; however, only half of the patients fully recover after treatment due to the problems associated with donor shortage, mismatch between the donor nerve and the injury site, immunological problems and the need for secondary surgeries. ${ }^{2,3}$ These problems have led to the development of alternative medical therapies focusing on biomaterials that are able to guide and direct neural cells to promote the recovery of motor or sensory functions., ${ }^{4,5}$ Biomaterials are used for the treatment of peripheral nerve injuries by repairing and regenerating damaged tissues by mimicking the native environment of neural cells. ${ }^{6,7}$ The extracellular matrix (ECM) acts as a structural support and includes a

Institute of Materials Science and Nanotechnology, National Nanotechnology Research Center (UNAM), Bilkent University, Ankara 06800, Turkey.

E-mail:moguler@unam.bilkent.edu.tr, atekinay@unam.bilkent.edu.tr, uyar@unam.bilkent.edu.tr

$\dagger$ Electronic supplementary information (ESI) available: LC-MS and experimental details are provided. See DOI: 10.1039/c6tb02441f wide range of polysaccharide chains and fibrous proteins that present biochemical and biomechanical cues for the proliferation, differentiation and migration of cells. ${ }^{8}$ Therefore, the design of bioactive, ECM-mimetic scaffolds can facilitate the attachment of cells, enable nutrient transport with their porous structure and provide relevant signals to cells. ${ }^{9}$

Electrospinning is a widely-used fabrication technique for producing fibers with diameters ranging from nanometers to micrometers. Due to its ease of control on the structural, mechanical and biological properties of the fabricated materials, electrospinning has been widely utilized for biomaterial production. ${ }^{10-12}$ The most common polymers used in the electrospinning process for nerve tissue-engineered grafts are poly(L-lactic acid) (PLLA), poly(lactic-co-glycolic-acid) (PLGA) and poly( $\varepsilon$-caprolactone) (PCL) due to their biodegradability and biocompatibility. ${ }^{13}$ However, the nonbioactive and hydrophobic nature of these polymers limits the cell-materials interactions, which may cause problems in the essential cellular bioprocesses for neural differentiation. ${ }^{14}$ In order to improve the hydrophilicity and bioactivity of electrospun polymeric materials, additional approaches such as chemical covalent binding, ${ }^{15}$ air plasma treatment ${ }^{16}$ and blending during electrospinning ${ }^{17}$ has been performed. Furthermore, electrospun nanofibers were chemically functionalized with laminin or laminin 
derived epitopes to promote neural cell affinity, recovery and neurite extension. ${ }^{18-20}$ Becker et al. functionalized PLLA fibers with a laminin derived epitope by click chemistry and showed the improved effect of the peptide conjugated fibers on neural cells in terms of neurite extension. ${ }^{19}$ In an alternative approach, Lee et al. applied an air plasma method using ammonia gas to develop electrospun PLGA scaffolds presenting amino-rich and hydrophilic surface characteristics for cellular adhesion and proliferation. ${ }^{21}$ However, adjusting the surface homogeneity and controlling the exposure time are challenging issues since air plasma affects only a limited depth of electrospun scaffolds. ${ }^{22}$ In addition to chemical conjugation approaches, Ramakrishna et al. prepared PCL nanofibers, which were either blended with laminin or encapsulated laminin in the core of PCL nanofibers by the electrospinning process. ${ }^{23}$ However, natural proteins are susceptible to denaturation during the electrospinning process, because of the harsh conditions of organic solvents. Besides functionalization, the orientation of the electrospun fibers is another important feature for designing biomaterials for neural tissue engineering. ${ }^{24,25}$ Uniaxially aligned fibers guide the regeneration of axons and induce the extension of the neurites along the direction of the scaffold, which is able to enhance the repair of nerve defects even in the presence of long peripheral nerve gaps. $^{26-28}$ Supramolecular host-guest chemistry is a novel surface functionalization method due to the high specificity of recognition motifs through noncovalent interactions. ${ }^{29}$ Cyclodextrins (CDs) are composed of glucopyranose subunits, and they are one of the most intriguing oligosaccharide types due to their ability to form noncovalent host-guest interaction complexes through their cyclic and truncated cone-shaped structures. $^{30-32}$ Due to the non-toxic and low-cost properties of CDs, which are obtained by the enzymatic degradation process of starch, they have been widely used in the pharmaceutical, food and cosmetic industries. ${ }^{32,33}$ One of the most well-known noncovalent host-guest interactions is observed between CD and adamantane molecules, in which the CD cavity serves as a host, while adamantane is a hydrophobic guest molecule. ${ }^{34}$ Stupp et al. used a similar approach to attach a biofunctional adamantane conjugated bioactive peptide epitope on CD surfaces in order to enhance focal adhesions of cells. ${ }^{35}$ Herein, we report for the first time a versatile and effective approach for the design of aligned electrospun CD nanofibers (CDNFs) functionalized with an adamantane-conjugated, laminin derived peptide epitope. In this system, the pentapeptide epitope Ile-Lys-Val-Ala-Val (IKVAV), a laminin derived sequence promoting neurite outgrowth, ${ }^{36,37}$ was utilized as the bioactive cue. In this study, aligned cyclodextrin nanofibers (CDNFs) were produced in environmentally friendly conditions and functionalized with adamantane-conjugated IKVAV epitopes through host-guest interactions. The electrospinning of FDA approved modified $\mathrm{CD}^{38,39}$ enabled us to obtain biocompatible high-aspect ratio CDNFs and a water-insoluble fibrous network with unique chemical and physical properties. ${ }^{40}$ We observed that biofunctionalized aligned electrospun CDNFs direct the adhesion and neurite outgrowth of neuronal progenitor PC12 cells by providing a synergistic combination of physical and chemical cues.

\section{Results and discussion}

Synthesis and characterization of IKVAV and KK peptides with random and aligned CDNFs

Adamantane (Ada), as a small guest hydrophobic molecule, is able to form a host-guest inclusion complex with CD due to its complementary size and high affinity to the hydrophobic CD cavity. ${ }^{36,37}$ As shown in Fig. 1, 1-adamantaneacetic acid units were covalently conjugated to two types of peptide backbones (either a control peptide (KK) or a laminin mimetic epitope (IKVAV), which is known to induce the differentiation of neural progenitor cells into neurons) using a 6-aminohexanoic acid molecule as a spacer. The KK peptide consists of the same backbone with a bioactive IKVAV peptide and has two positive charges under physiological conditions (Fig. 1a and b). It was designed as an epitope-free control to examine the effects of biochemical and biophysical cues on the neural differentiation capacity of the cells. Two glycine residues were conjugated between hydrophilic amino acid residues and the hydrophobic group to ensure that the bioactive cues are displayed on the surface. The peptide molecules were synthesized by using a solid phase peptide synthesis method, purified by HPLC and characterized by LC-MS (Fig. S1, ESI $\dagger$ ).

The functionalization of the polymer nanofiber surface was achieved through host-guest interactions following the incubation of electrospun CDNFs in peptide solutions (Fig. 1c). Nile red assay ${ }^{38}$ was used to determine the optimal peptide concentrations for minimizing aggregation and promoting the free integration of soluble peptide molecules into $\mathrm{CD}$ cavities. Critical aggregation concentrations (CACs) of IKVAV and KK peptides were determined as $60 \mu \mathrm{M}$ and $125 \mu \mathrm{M}$, respectively (Fig. S2, ESI $\dagger$ ). Therefore, CDNFs were incubated with $50 \mu \mathrm{M}$ IKVAV and KK peptides for $24 \mathrm{~h}$. The binding affinity of adamantane conjugated IKVAV and KK peptides to soluble CD was determined by ITC measurements (Fig. S3, ESI $\dagger$ ). The inclusion complex was found to form at a 1:1 molar ratio. In addition, the association constants of IKVAV and KK peptides

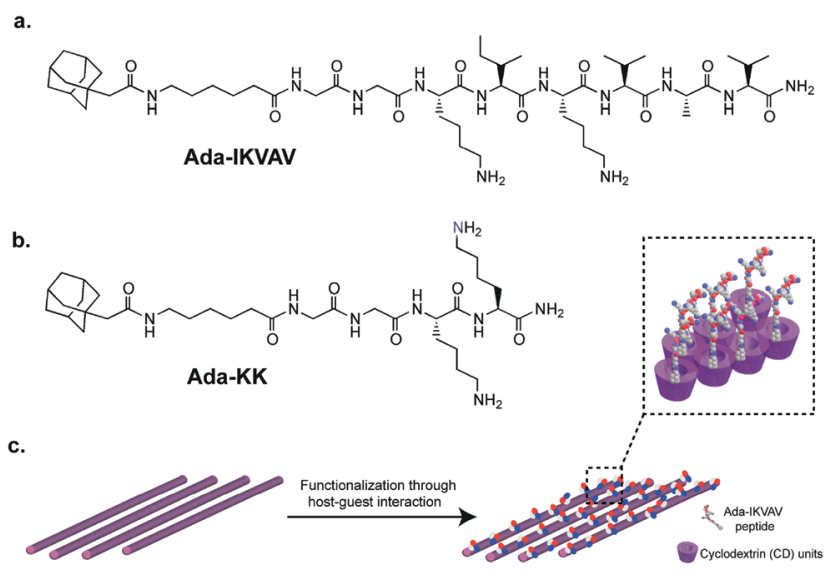

Fig. 1 Chemical representation of (a) adamantane-6-aminohexanoic acid-GGKIKVAV-Am (IKVAV) and (b) adamantane-6-aminohexanoic acidGGKK-Am (KK). (c) Schematic representation of electrospun and aligned CDNFs and the host-guest interaction with the bioactive peptide epitope. 


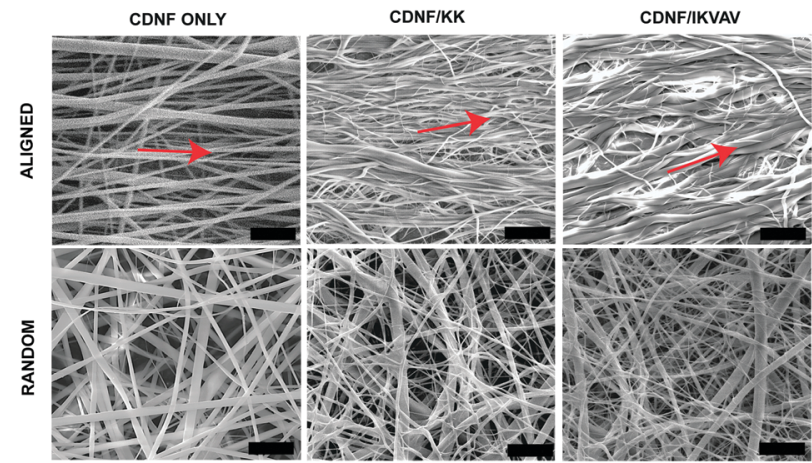

Fig. 2 Scanning electron microscopy (SEM) images of random and aligned CDNFs with peptide functionalized forms (scale bars: $10 \mu \mathrm{m}$ ). Red arrows show the alignment direction.

were found to be $\log K_{\mathrm{a}_{\mathrm{IVVAV}}}=4.11$ and $\log K_{\mathrm{a}_{\mathrm{KK}}}=4.08$ respectively, which are comparable with association constants reported previously. ${ }^{39}$ The structural properties of non-functionalized CDNFs and peptide-functionalized materials were also analyzed by SEM (Fig. 2). The images revealed that there is no significant difference between the groups in terms of the fiber diameter, which is close to $1 \mu \mathrm{m}$ (Fig. S4, ESI $\dagger$ ). Furthermore, noncovalent functionalization of CDNFs with peptide molecules did not cause any significant changes in the morphology of the CDNFs (Fig. 2 and Fig. S4, ESI $\dagger$ ). The presentation of peptide molecules on electrospun CDNFs through host-guest interactions was shown using a fluorescently labeled IKVAV peptide (FITC-IKVAV). After the incubation of both aligned and random CDNFs in peptide solution for $24 \mathrm{~h}$, the confocal images of the samples were acquired to monitor the distribution of the peptides on CDNFs. Fluorescently labeled bioactive peptide molecules were homogenously distributed on both aligned and random electrospun CDNFs (Fig. 3a and b).
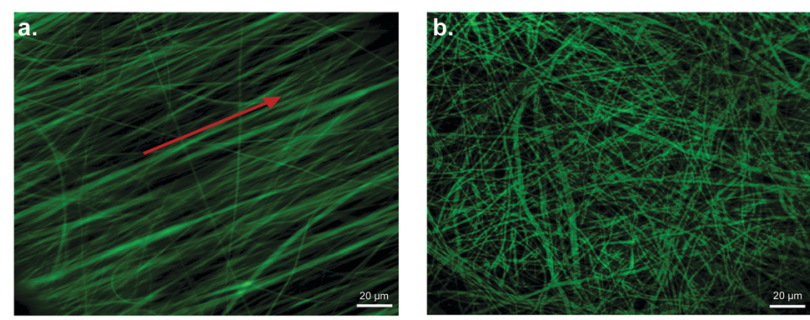

c.

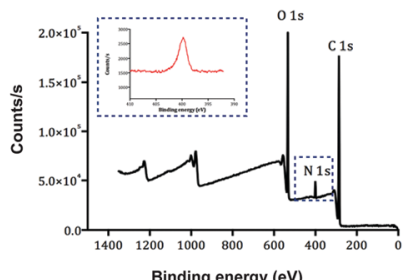

d.

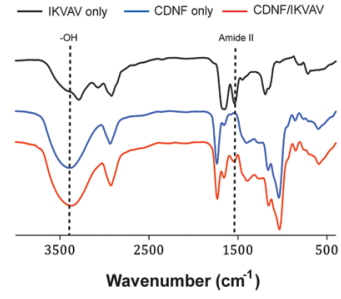

Fig. 3 Aligned (a) and random (b) CDNFs functionalized with fluorescently labeled IKVAV. The red arrow shows the alignment direction. (c) XPS spectra of functionalized and aligned CDNFs. The inset shows the N1s (red line) peak and the presence of the peptide on the surface. (d) FTIR spectra of IKVAV, CDNFs and CDNFs/IKVAV.
In addition to fluorescence imaging, surface characterization of the samples was also performed by XPS. Both random and aligned CDNFs showed only carbon and oxygen atoms (Fig. S5a and d, ESI $\dagger$ ). On the other hand, functionalization of random and aligned CDNFs with KK and IKVAV peptides (Fig. S5b and c, ESI $\dagger$ ) revealed an additional nitrogen peak indicating the existence of a peptide layer on the surface (Fig. 3c).

To further investigate the formation of inclusion complexes between CDNFs and the peptide moieties, the FT-IR spectra of the samples were obtained for both aligned and random morphologies (Fig. 3d and Fig. S6, ESI†). In the case of bare CDNFs, a wide IR absorption band is present at $3390 \mathrm{~cm}^{-1}$ due to the bending vibration of the $-\mathrm{OH}$ group. However, peptide functionalization resulted in the red-shift of the peak position from $3390 \mathrm{~cm}^{-1}$ to $3346 \mathrm{~cm}^{-1}$ due to the interactions between adamantane-peptide conjugates and the hydroxyl groups of CDNFs. In addition, the IR spectrum of the peptide-only group showed a typical amide II peak around $1533 \mathrm{~cm}^{-1}$ due to $\mathrm{N}-\mathrm{H}$ bending. ${ }^{40}$ A prominent amide II characteristic band is also present in the IR spectrum of peptide-functionalized CDNFs, further demonstrating the successful attachment of peptide molecules to the electrospun fibers. The peptide content in this system was quantitatively determined by elemental analysis. The carbon, hydrogen, and nitrogen weight percentages within the samples are shown in Table S1 (ESI $\dagger$ ). In contrast, nitrogen could not be detected on random and aligned non-functionalized CDNFs due to the absence of peptide materials. KK and IKVAV peptide amounts were calculated as $32.90 \%(\mathrm{w} / \mathrm{w})$ and $30.62 \%(\mathrm{w} / \mathrm{w})$ within random CDNFs; and 30.95\% (w/w) and 30.81\% (w/w) within the aligned CDNFs, respectively (Table S2, ESI $\dagger$ ).

Surface wettability is another important property of prospective biomaterials, as it is known to enhance the cellular viability, adhesion and differentiation by effectively facilitating cell membrane-surface interactions. ${ }^{41}$ Therefore, the surface hydrophilicity of both random and aligned CDNFs was investigated through contact angle measurements (Fig. S7, ESI $)$ ). Electrospun CDNFs with random and aligned fiber orientations were both strongly hydrophilic without requiring any additional treatments such as air plasma treatment, immobilization of proteins and chemical modifications. ${ }^{42}$ Hence, the surface hydrophilicity of the electrospun CDNFs was found to be compatible with cellular interactions and can be used for cellular differentiation studies.

\section{Biocompatibility of electrospun CDNFs}

The ability of electrospun CDNFs to induce neurite outgrowth and neural differentiation was evaluated using the PC-12 cell line, which differentiates into neural cells in the presence of soluble or substrate-derived physical and chemical factors. Fig. 4 sho-ws the biocompatibility and adhesion behaviors of the electrospun CDNFs in random and aligned fiber orientations and presenting either IKVAV or KK peptides. We observed that cellular viabilities on the scaffolds were comparable with poly-D-lysine (PDL) coated surfaces prepared as positive control (Fig. 4a and Fig. S8a, ESI $\dagger$ ), suggesting that the materials are biocompatible.

The adhesion profiles of PC-12 cells cultured on CDNFs were also investigated, because differentiation of these cells requires 


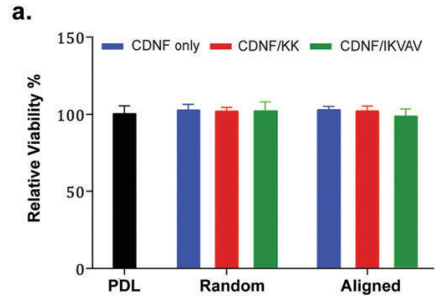

b.

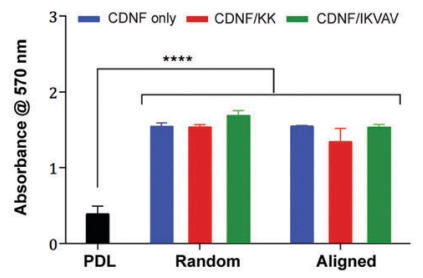

Fig. 4 (a) The relative viability of PC-12 cells cultured on random and aligned CDNFs, with or without peptide functionalization, compared to the control group treated with poly-D-lysine (PDL) at $24 \mathrm{~h}$ and (b) adhesion profiles of PC-12 cells after $2 \mathrm{~h}$ of incubation.

their attachment to a substrate. Adhesion assay results revealed that electrospun CDNFs facilitated the attachment of PC-12 cells to a greater extent than PDL coated cover slips (Fig. $4 \mathrm{~b}$ and Fig. S8b, ESI $\dagger$ ). The promoted cellular adhesion behavior on the scaffolds could be due to the affinity of cholesterol molecules located on the cell membrane to the hydrophobic cavity of CDNFs. $^{43,44}$

\section{Differentiation of PC-12 cells}

Neural differentiation of PC-12 cells on CDNFs was studied by immunostaining of the cells against synaptophysin I antibody, which is the most abundant protein at pre-synaptic axon terminals (Fig. 5). ${ }^{45}$ Synaptophysin expression was visualized to determine whether neurite outgrowth was enhanced on aligned CDNFs (Fig. 5a). The role of CDNFs in directing neurite outgrowth was investigated by measuring the neurite lengths of PC-12 cells in order to gain quantitative information about neural differentiation.

Neurite extension lengths on aligned and IKVAV-functionalized CDNFs were nearly two times longer than non-functionalized and KK-functionalized random CDNFs (Fig. 5b). Among the aligned CDNFs, IKVAV functionalized CDNFs induced significantly longer neurites, which underlines the importance of the bioactive epitope. In addition, the importance of fiber morphology was evident when the results were compared between random and aligned IKVAV-functionalized CDNFs (Fig. 5b). Biofunctionalization and alignment also had a synergistic effect on the number of neuritebearing cells (Fig. 5b). Within each group the highest number of neurite-bearing cells was observed on the biofunctionalized scaffolds, while aligned CDNFs were found to further enhance this effect. These results suggest that both fiber alignment and biofunctionalization significantly promote the neural differentiation of PC-12 cells on electrospun scaffolds. The expression of the neural differentiation markers $\beta$ III-tubulin and SYN1 was also quantified at day 7 to determine the effect of biofunctionalized and aligned scaffolds on the genetic regulation of neurite a.
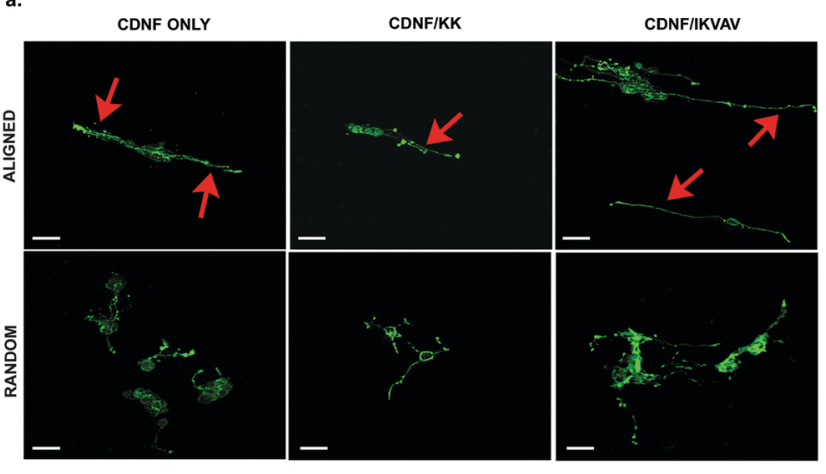

b.

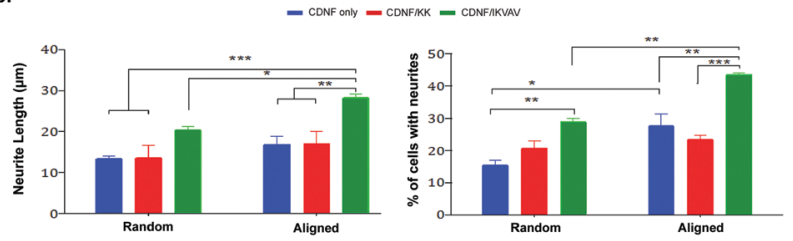

Fig. 5 (a) Synaptophysin expression of PC-12 cells cultured on random and aligned CDNFs with bioactive and non-bioactive functionalized peptide groups. Scale bars: $40 \mu \mathrm{m}$. (b) Neurite length and percentage of neurite bearing cells quantified using Image $J$ at day 7 after induction revealing that the aligned CDNFs functionalized with IKVAV are the most suitable scaffold for neurite outgrowth.

extension. When PC-12 cells were cultured on the aligned CDNFs/IKVAV, the expression of the pre-synaptic axon terminal marker SYN1 was upregulated by $\sim 5.5$ - and 4.4-folds compared to PC-12 cells cultured on random CDNFs only and the CDNFs/ KK surface, respectively (Fig. 6a). In addition, the alignment of the fibers also had a significant effect on the upregulation of SYN1, as PC-12 cells on aligned CDNFs/IKVAV surfaces exhibit a 2.3-fold increase in SYN1 expression compared to the random CDNFs/IKVAV. In parallel with SYN1 expression, $\beta I I I-t u b u l i n$

a.

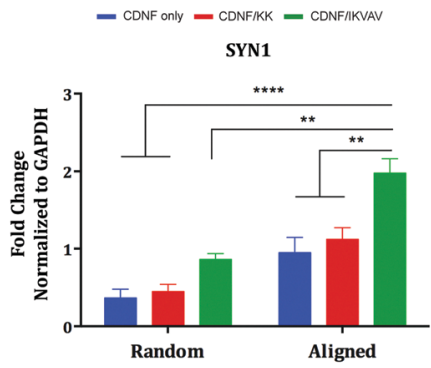

b.

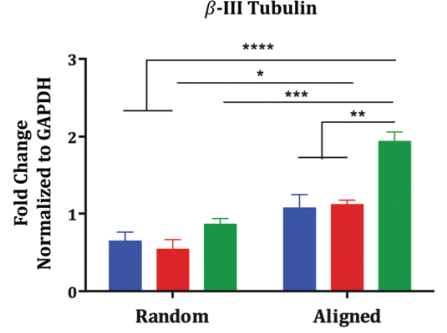

Fig. 6 Expression of (a) SYN1 and (b) $\beta$-III tubulin normalized to control gene GAPDH. The values represent mean \pm SEM (****, $p<0.0001$; $\star * *, p<0.001 ; * *, p<0.01$; and *, $p<0.05)$. 
expression of cells cultured on aligned CDNFs/IKVAV scaffolds was increased 3- and 3.6-folds compared to random CDNFs only group and the CDNFs/KK, respectively (Fig. 6b). Even in the absence of a biofunctionality, a 2-fold increment difference was observed between random and aligned CDNFs/KK for $\beta$ III-tubulin expression, highlighting the importance of their topological structure. Overall, we conclude that the neuroinductive effect of fiber alignment is more pronounced when biofunctional epitopes are presented on the surface of CDNFs.

\section{Conclusions}

Herein, we report the production of aligned CDNFs under environmentally friendly conditions and functionalization of these nanofibers with a laminin-derived epitope through hostguest chemistry for the enhancement of neural differentiation in vitro. The CDNFs/IKVAV hybrid system exhibited no toxicity to PC-12 cells, and provided an ideal environment for the induction of neuritogenesis through a combination of topographical and biochemical factors. The synergistic effect of biochemical and morphological cues facilitated the development of longer neurites than those obtained using only the fiber alignment or bioactive signals for the induction of differentiation. In addition, we showed that neural differentiation was guided not only by the signals presented on the surface of CDNFs, but also through its interplay with the structural orientation of electrospun CDNFs. The biofunctionalized aligned CDNFs can be used as a potential material for nerve grafts and functional recovery in neural tissue engineering.

\section{Experimental}

\section{Materials}

All protected amino acids, Fmoc-6-aminohexanoic acid, Rink amide MBHA resin, 1-adamantaneaceticacid, fluorescein isothiocyanate isomer I (FITC), $N, N, N^{\prime}, N^{\prime}$-tetramethyl-O-( $1 H$-benzotriazole1-yl)uronium hexafluorophosphate (HBTU) and diisopropylethylamine (DIEA) were purchased from Novabiochem, ABCR or Sigma-Aldrich. Hydroxypropyl- $\beta$-cyclodextrin (HP $\beta C D$ ) (degree of substitution: $\sim 0.6$, Cavasol ${ }^{\mathrm{R}}$ W7 HP Pharma) was kindly donated by Wacker Chemie AG (Germany). 1,2,3,4-Butanetetracarboxylic acid (BTCA, 99\%) and sodium hypophosphite hydrate were commercially obtained from Sigma-Aldrich. All other chemicals and materials used in this study were of analytical grade and purchased from Invitrogen, Fisher, Merck, Alfa Aesar, and/or Sigma-Aldrich.

\section{Synthesis and characterization of peptides}

The Fmoc solid phase peptide synthesis method was used in order to synthesize adamantane-6-aminohexanoicacid-Gly-Gly-LysIle-Lys-Val-Ala-Val-Am (IKVAV), adamantane-6-aminohexanoicacidGly-Gly-Lys-Lys-Am (KK) and adamantane-6-aminohexanoicacidGly-Gly-Lys-Lys(FITC)-Ile-Lys-Val-Ala-Val-Am (FITC-IKVAV). Rink amide MBHA resin (Novabiochem) served as a solid support for the synthesis of all peptide molecules. In order to activate carboxylate groups 2 mole equivalents of amino acid, 3 mole equivalents of diisopropylethylamine (DIEA) and 1.95 mole equivalents of $N, N, N^{\prime}, N^{\prime}$-tetramethyl-O-(1H-benzotriazole-1-yl)uronium hexafluorophosphate (HBTU) were used for 1 mole equivalent of solid resin. For each coupling step, $10 \%$ acetic anhydride-DMF solution was used to acetylate the unreacted amine groups, and Fmoc protecting groups were removed with $20 \%$ piperidine/dimethylformamide (DMF) for $20 \mathrm{~min}$. The coupling time for the amino acids and Fmoc-6-aminohexanoic acid was $2 \mathrm{~h}$ for each cycle. The coupling mechanism of 1-adamantaneacetic acid was similar to the amino acid coupling steps. Between each of these steps, resins were washed three times using DMF, DCM and DMF, respectively. For FITC conjugation with the IKVAV peptide, the 4-methyltrityl (Mtt) protecting group of -Lys was removed using $60 \mathrm{~mL}$ of cleavage solution containing $2.85 \mathrm{~mL}$ of TFA, $0.075 \mathrm{~mL}$ of distilled water, $0.075 \mathrm{~mL}$ of triisopropylsilane and $57 \mathrm{~mL}$ of DCM. The resins were shaken with $10 \mathrm{~mL}$ of this solution 6 times for $5 \mathrm{~min}$ each, and then washed with DCM until the yellow color in the washing DCM solution had disappeared. Finally, the resins were washed with $5 \%(\mathrm{v} / \mathrm{v})$ DIEA in DCM prior to FITC coupling. The FITC coupling solution containing $389.4 \mathrm{mg}$ of FITC and $256.8 \mu \mathrm{L}$ of DIEA was prepared in $3 \mathrm{~mL}$ of DMF and added to the resins. The reaction vessel was covered with aluminum foil in order to prevent the bleaching of FITC. For scaffold functionalization studies, FITC was combined with IKVAV at a ratio of $5 \mathrm{~mol} \%$. After the completion of the synthesis, peptides were cleaved from the solid supports with a solution of $95 \%$ trifluoroacetic acid (TFA), 2.5\% distilled water, and 2.5\% triisopropylsilane. The cleavage reaction was continued for $3 \mathrm{~h}$ by shaking the resins with the cleavage solution. Then, the resins were washed with DCM to collect the cleaved peptides into the flask. Excess TFA and DCM were removed using a rotary evaporator, and peptides were precipitated in ice-cold diethyl ether overnight. To remove ether, centrifugation was performed at $8000 \mathrm{rpm}$ for $20 \mathrm{~min}$. The precipitated peptides were dissolved in distilled water and kept at $-80{ }^{\circ} \mathrm{C}$ overnight. The lyophilization of the frozen peptide solutions was carried out for 3 days in order to obtain dried peptide powders. The purity of the peptides was determined using an Agilent 6530 quadruple time of flight (Q-TOF) mass spectrometer equipped with an electrospray ionization (ESI) source. Further purification was performed with a preparative HPLC system (Agilent 1200 series).

\section{Electrospinning of cyclodextrin nanofibers (CDNFs)}

Crosslinked water-insoluble CDNFs were obtained by electrospinning an aqueous HPßCD solution, and BTCA was used as a cross-linker. The electrospinning parameters were adjusted as follows: $0.5-2 \mathrm{~mL} \mathrm{~h}^{-1}$ flow rate, $10-20 \mathrm{kV}$ applied voltage and 10-20 cm collector distance. Randomly oriented CDNFs were deposited on a grounded fixed metal collector, while a rotating drum at a speed of $2000 \mathrm{rpm}$ was used to obtain aligned CDNFs.

\section{Critical aggregation concentration (CAC) determination}

A hydrophobic Nile red (9-diethylamino-5-benzo[ $\alpha]$ phenoxazinone) fluorescence probe assay was performed to determine the transition phase between peptide assemblies and facilitate 
greater control over scaffold morphology. Peptide solutions (ranging from $1 \mathrm{mM}$ to $0.244 \mu \mathrm{M}$ ) were prepared in distilled water at around $\mathrm{pH} 7$, while a $1.25 \mathrm{mM}$ stock solution of Nile red was prepared in ethanol $(1 \mathrm{~mL})$ and then diluted to $78.12 \mu \mathrm{M}$ by using ethanol. Peptide solutions prepared at different concentrations were mixed with the same amount of dye solution and incubated overnight at room temperature. The final Nile red concentration in the mixture was $250 \mathrm{nM}$, and $0.31 \%(\mathrm{v} / \mathrm{v})$ ethanol was present in the solutions. A Cary Eclipse spectrophotometer was used to collect the emission spectra between $580 \mathrm{~nm}$ and $750 \mathrm{~nm}$ with an excitation at $550 \mathrm{~nm}$.

\section{Functionalization of CDNFs with peptides}

Electrospun CDNFs were washed with ethanol and water, immersed in the peptide solutions (IKVAV or KK) and incubated for $24 \mathrm{~h}$ in order to functionalize CDNF surfaces with peptide molecules through host-guest interactions at a $1: 1$ molar ratio.

\section{Scanning electron microscopy (SEM)}

Morphologies of CDNFs and peptide-functionalized CDNFs were analyzed with a FEI Quanta 200 FEG scanning electron microscope. All samples were coated with $8 \mathrm{~nm} \mathrm{Au-Pt}$ prior to imaging and the analysis was performed at $15 \mathrm{kV}$. The diameters of electrospun fibers were quantified using ImageJ software by measuring the diameters of $30 \times 8$ nanofibers from eight different SEM images.

\section{X-ray photoelectron spectroscopy (XPS)}

XPS analyses of samples were conducted by using a Thermo K-alpha monochromated high performance X-ray photoelectron spectrometer. CDNFs and peptide-immobilized systems were analyzed after washing. Survey analyses were performed at 3 scans. High-resolution spectra of carbon and oxygen were recorded at 10 scans, while that of nitrogen was recorded at 15 scans.

\section{FT-IR spectroscopy}

A Fourier transform infrared (FT-IR) spectrometer (Bruker-Tensor 37) was used for the collection of IR spectra of the samples. Non-functionalized and peptide functionalized CDNFs prepared in both aligned and random electrospun fiber orientations were mixed with potassium bromide $(\mathrm{KBr})$ and pressed to prepare the pellets. The IR spectra were recorded between 4000 and $400 \mathrm{~cm}^{-1}$ at a resolution of $4 \mathrm{~cm}^{-1}$ with 64 scans recorded for each sample.

\section{Elemental analysis}

After host-guest functionalization, the peptide content in electrospun CDNFs was analyzed using a Thermo Scientific FLASH 2000 series CHNS-O analyzer. Both random and aligned CDNFs and their peptide-functionalized forms were analyzed. As a standard, 2,5-(bis(5-tert-butyl-2-benzo-oxazol-2-yl))thiophene was used as a standard. For each analysis, vanadium pentoxide was used as a catalyst for complete oxidation.

\section{Isothermal titration calorimetry}

Stoichiometry and association constants between CD units and guest peptides (IKVAV and KK) were determined using an ITC (Microcal ITC200). $40 \mu \mathrm{L}$ of $5 \mathrm{mM}$ CD solution was injected in $1.5 \mu \mathrm{L}$ increments into cells containing $280 \mu \mathrm{L}$ of $350 \mu \mathrm{M}$ IKVAV or $700 \mu \mathrm{M} \mathrm{KK}$ solutions. During the measurements, the cell temperature was $25{ }^{\circ} \mathrm{C}$, the reference power was $3.5 \mathrm{mcal} \mathrm{s}^{-1}$, and the stirring speed was $1000 \mathrm{rpm}$.

\section{Contact angle measurements}

The wettability of electrospun CDNFs was measured using an optical contact angle measurement system (Dataphysics OCA30). Ultra-pure water was used as the testing liquid.

\section{Fluorescence imaging}

The functionalization of CDNFs with the peptide molecules through host-guest interactions was also done by incubating the FITC conjugated IKVAV peptide with the electrospun CDNFs overnight. The electrospun CDNFs were washed with ethanol and water prior to imaging. Fluorescence images were acquired using a Zeiss LSM510 microscope under $20 \times$ magnification. Peptide solutions used for the fluorescence imaging were prepared by mixing FITC-IKVAV with the non-labeled IKVAV peptide at a $1: 19$ molar ratio, respectively.

\section{Cell viability and adhesion assays}

PC-12 cellular viability and adhesion analyses were performed in a 48-well plate. Before cell culture experiments, $9 \mathrm{~mm}$ cover slips coated with a parafilm were immersed in $96 \%(\mathrm{v} / \mathrm{v})$ ethanol solution for $30 \mathrm{~min}$ and sterilized with UV irradiation for $15 \mathrm{~min}$. Coverslip-sized electrospun nanofiber mats were cut and treated with $70 \%(\mathrm{v} / \mathrm{v})$ ethanol for $30 \mathrm{~min}$ for sterilization. Then, the scaffolds were exposed to cell culture medium at $37{ }^{\circ} \mathrm{C}$ for 6 h. PC- 12 cells $\left(5.0 \times 10^{4}\right.$ per well $)$ were seeded on the electrospun scaffolds containing Roswell Park Memorial Institute medium (RPMI) with 10\% horse serum (HS), 5\% fetal bovine serum (FBS), $2 \mathrm{mM}$ L-glutamine and 1\% penicillin/streptomycin $(\mathrm{P} / \mathrm{S})$, and incubated at $37{ }^{\circ} \mathrm{C}$ in $5 \%(\mathrm{v} / \mathrm{v}) \mathrm{CO}_{2}$ for $24 \mathrm{~h}$ and $48 \mathrm{~h}$. The MTT (3-(4,5-dimethylthiazol-2-yl)-2,5-diphenyltetrazolium bromide) method was used to evaluate the activity of cells on the electrospun fibers. $270 \mu \mathrm{L}$ of DMEM (Dulbecco's Modified Eagle's Medium) without phenol red and $30 \mu \mathrm{L}$ of MTT were added into each well and cultivated for $4 \mathrm{~h}$ under standard cell culture conditions. The nutrient solution was completely removed, and $300 \mu \mathrm{L}$ of MTT solubilization solution was added into each well and pipetted at constant temperature in order to dissolve the crystals. The purple solution was transferred into a 96-well culture plate (200 $\mu \mathrm{L}$ per well), and its absorbance was measured at $570 \mathrm{~nm}$ using a microplate reader (M5, Molecular Devices). The cell adhesion assay was performed as previously described. ${ }^{46}$ Briefly, the cells were incubated with $4 \mathrm{mg} \mathrm{mL} \mathrm{m}^{-1}$ BSA and $50 \mu \mathrm{g} \mathrm{mL}^{-1}$ cyclohexamide in serum-free medium for $2 \mathrm{~h}$ and $4 \mathrm{~h}$ at $37{ }^{\circ} \mathrm{C}$ with $5 \% \mathrm{CO}_{2}$. Then, $500 \mu \mathrm{L}$ of PC-12 cells $\left(1 \times 10^{5}\right.$ cells per $\left.\mathrm{mL}\right)$ were seeded with medium containing $4 \mathrm{mg} \mathrm{mL} \mathrm{m}^{-1}$ BSA and $50 \mu \mathrm{g} \mathrm{mL}{ }^{-1}$ cyclohexamide for $2 \mathrm{~h}$. 
After incubation, the unattached cells were washed with PBS twice. The attached cells were fixed with $4 \%$ formaldehyde in PBS for $15 \mathrm{~min}$ and then stained with $0.5 \%$ crystal violet for $1 \mathrm{~h}$. After that point, the experiment was conducted under dark conditions. The plates were gently washed with distilled water five times and cellular membranes were disrupted with $2 \%$ SDS for $10 \mathrm{~min}$. Absorbance was measured at $570 \mathrm{~nm}$ with a M5 microplate reader.

\section{Immunocytochemistry (ICC)}

Prior to neural induction, PC-12 cells $\left(5 \times 10^{4}\right.$ per well) were cultured on the materials for $24 \mathrm{~h}$ under standard cell culture conditions. Then the medium was replaced with freshly prepared neural induction medium containing MEM with $2 \%$ HS, 1\% FBS, 2 mM L-glutamine, 1\% P/S and $20 \mathrm{ng} \mathrm{mL} \mathrm{m}^{-1} \mathrm{NGF}$. The cells were cultured on the materials for seven days and fixed with $500 \mu \mathrm{L}$ per well pre-warmed $4 \%$ paraformaldehyde/ PBS for $15 \mathrm{~min}$ at room temperature. After discarding paraformaldehyde, the cells were washed with $0.3 \%$ Triton-X100/ PBS for $15 \mathrm{~min}$ at room temperature on a shaker. Then, blocking was carried out with $10 \%$ normal goat serum (NGS) and $1 \%$ bovine serum albumin (BSA) in PBS with $0.3 \%$ Triton-X for $1 \mathrm{~h}$ at room temperature on a shaker. After aspirating the blocking solution, the cells were treated with primary antibodies against synaptophysin at 1:400 dilution. The cell culture plates were sealed with a parafilm and incubated overnight at $4{ }^{\circ} \mathrm{C}$ on a nutator shaker. On the next day, the plates were incubated for $1 \mathrm{~h}$ at room temperature. Then, cells were washed with $0.3 \% \mathrm{PBS} /$ Triton-X100 for $5 \mathrm{~min}$ and twice with PBS for $5 \mathrm{~min}$ on a rocking shaker. After this point, the experiment was continued in the dark. A secondary antibody (GAR AF488) in 10\% BSA was added to the wells and incubated for $1 \mathrm{~h}$. The washing steps were again performed with PBS and finally distilled water on the shaker. A drop of Prolong Gold Mounting Medium was added onto the slides of each coverslip. The coverslips were then taken out from each well, inverted and exposed to a mounting solution on slides. 8 images were acquired for each well with a Zeiss LSM510 confocal microscope under $20 \times$ magnification. Neurite extensions were quantified using Image $\mathrm{J}$, and the average neurite length was obtained from three independent replicates.

\section{Quantitative reverse transcription polymerase chain reaction (qRT-PCR)}

Synaptophysin and $\beta$ III-tubulin gene expression profiles were examined by qRT-PCR. Total RNA of the differentiated PC-12 cells was isolated on day 7 using TRIzol reagent (Invitrogen) according to the manufacturer's protocol. The yield and purity of the isolated RNA were quantified using a Nanodrop 2000 (Thermo Scientific). Primer sequences were designed using the NCBI database (Table S3, ESI $\dagger$ ). The SuperScript III Platinum SYBR Green one-step qRT-PCR kit was used to conduct qRT-PCR. Temperature cycling for the reaction was done as $50{ }^{\circ} \mathrm{C}$ for $3 \mathrm{~min}$, $95{ }^{\circ} \mathrm{C}$ for $5 \mathrm{~min}, 40$ cycles of $95{ }^{\circ} \mathrm{C}$ for $15 \mathrm{~s}, T_{\mathrm{m}}\left(58.0{ }^{\circ} \mathrm{C}\right.$ for synaptophysin and $\beta$ III-tubulin) for $30 \mathrm{~s}$, and $40{ }^{\circ} \mathrm{C}$ for $1 \mathrm{~min}$, respectively. Amplification was analyzed by determining the binding of SYBR I to double stranded DNA. Gene expressions were normalized with GAPDH as the internal control gene.

\section{Statistical analysis}

All experiments were independently repeated at least twice with at least three replicates for each experimental group. All quantitative results were expressed as \pm standard error of mean (SEM). Statistical analyses were carried out by one-way or two-way analysis of variance (ANOVA), whichever was applicable.

\section{Acknowledgements}

This work was partially supported by the Scientific and Technological Research Council of Turkey (TUBITAK) and the Turkish National Academy of Sciences (TUBA). We thank Melike Sever and Gokhan Gunay for helpful scientific discussions and gene expression analysis. We also thank Zeynep Erdogan for help with ITC and LC-MS.

\section{Notes and references}

1 S. Thuret, L. D. F. Moon and F. H. Gage, Nat. Rev. Neurosci., 2006, 7, 628.

2 A. C. De Luca, S. P. Lacour, W. Raffoul and P. G. di Summa, Neural Regener. Res., 2014, 9, 1943.

3 X. Gu, F. Ding, Y. Yang and J. Liu, Prog. Neurobiol., 2011, 93, 204.

4 C. M. Kelleher and J. P. Vacanti, J. R. Soc., Interface, 2010, 7, 717-729.

5 D. E. Ingber, V. C. Mow, D. Butler, L. Niklason, J. Huard, J. Mao, I. Yannas, D. Kaplan and G. Vunjak-Novakovic, Tissue Eng., 2006, 12, 3265.

6 B. Mammadov, M. Sever, M. O. Guler and A. B. Tekinay, Biomater. Sci., 2013, 1, 1119.

7 R. Bellamkonda, Biomaterials, 2006, 27, 3515.

8 C. Frantz, K. M. Stewart and V. M. Weaver, J. Cell Sci., 2010, 123, 4195.

9 N. J. Gardiner, Dev. Neurobiol., 2011, 71, 1054.

10 S. Ramakrishna and K. Fujihara, An Introduction to Electrospinning and Nanofiber, World Scientific, 2005.

11 A. Greiner and J. H. Wendorff, Angew. Chem., 2007, 46, 5670.

12 R. Garifullin, O. Ustahuseyin, A. Celebioglu, G. Cinar, T. Uyar and M. O. Guler, RSC Adv., 2013, 3, 24215.

13 S. Agarwal, J. H. Wendorff and A. Greiner, Polymer, 2008, 49, 5603.

14 C. Cunha, S. Panseri and S. Antonini, Nanomed.: Nanotechnol., Biol. Med., 2011, 7, 50.

15 D. Liang, B. S. Hsiao and B. Chu, Adv. Drug Delivery Rev., 2007, 59, 1392.

16 H. C. Ni, Z. Y. Lin, S. H. Hsu and I. M. Chiu, Acta Biomater., 2010, 6, 2066.

17 H. S. Yoo, T. G. Kim and T. G. Park, Adv. Drug Delivery Rev., 2009, 61, 1033. 
18 L. Yao, S. Wang, W. Cui, R. Sherlock, C. O’Connell, G. Damodaran, A. Gorman, A. Windebank and A. Pandit, Acta Biomater., 2009, 5, 580.

19 L. a. Smith Callahan, S. Xie, I. a. Barker, J. Zheng, D. H. Reneker, A. P. Dove and M. L. Becker, Biomaterials, 2013, 34, 9089.

20 H. S. Koh, T. Yong, C. K. Chan and S. Ramakrishna, Biomaterials, 2008, 29, 3574.

21 H. Park, J. W. Lee, K. E. Park, W. H. Park and K. Y. Lee, Colloids Surf., B, 2010, 77, 90.

22 W. Zhao, J. Li, K. Jin, W. Liu, X. Qiu and C. Li, Mater. Sci. Eng., C, 2016, 59, 1181.

23 E. Kijenska, M. P. Prabhakaran, W. Swieszkowski, K. J. Kurzydlowski and S. Ramakrishna, Eur. Polym. J., 2014, 50, 30.

24 T. B. Bini, S. Gao, S. Wang and S. Ramakrishna, J. Mater. Sci., 2006, 41, 6453.

25 J. Xie, W. Liu, M. R. Macewan, P. C. Bridgman and Y. Xia, ACS Nano, 2015, 8, 1878.

26 Y. Kim, V. K. Haftel, S. Kumar and R. V. Bellamkonda, Biomaterials, 2008, 29, 3117.

27 A. Hurtado, J. M. Cregg, H. B. Wang, D. F. Wendell, M. Oudega, R. J. Gilbert and J. W. McDonald, Biomaterials, 2011, 32, 6068.

28 H. B. Wang, M. E. Mullins, J. M. Cregg, A. Hurtado, M. Oudega, M. T. Trombley and R. J. Gilbert, J. Neural Eng., 2009, 6, 16.

29 B. V. K. J. Schmidt, M. Hetzer, H. Ritter and C. Barner-Kowollik, Prog. Polym. Sci., 2014, 39, 235.

30 A. Celebioglu and T. Uyar, Chem. Commun., 2010, 46, 6903.

31 C. Stoffelen and J. Huskens, Small, 2016, 12, 96.
32 Q. Hu, G. Tang and P. K. Chu, Acc. Chem. Res., 2014, 47, 2017.

33 J. Boekhoven, C. M. Rubertpérez, S. Sur, A. Worthy and S. I. Stupp, Angew. Chem., 2013, 52, 12077.

34 B. Mammadov, R. Mammadov, M. O. Guler and A. B. Tekinay, Acta Biomater., 2012, 8, 2077.

35 G. A. Silva, C. Czeisler, K. L. Niece, E. Beniash, D. A. Harrington, J. A. Kessler and S. I. Stupp, Science, 2004, 303, 1352.

36 M. Paolino, F. Ennen, S. Lamponi, M. Cernescu, B. Voit, A. Cappelli, D. Appelhans and H. Komber, Macromolecules, 2013, 46, 3215.

37 C. B. Rodell, J. E. Mealy and J. A. Burdick, Bioconjugate Chem., 2015, 26, 2279.

38 I. N. Kurniasih, H. Liang, P. C. Mohr, G. Khot, J. P. Rabe and A. Mohr, Langmuir, 2015, 31, 2639.

39 M. R. Eftink, M. L. Andy, K. Bystrom, H. D. Perlmutter and D. S. Kristol, J. Am. Chem. Soc., 1989, 111, 6765.

40 S. E. Paramonov, H. Jun and J. D. Hartgerink, J. Am. Chem. Soc., 2006, 128, 7291.

41 A. Martins, E. D. Pinho, S. Faria, I. Pashkuleva, A. P. Marques, R. L. Reis and N. M. Neves, Small, 2009, 5, 1195. 42 Z. Ma, Z. Mao and C. Gao, Colloids Surf., B, 2007, 60, 137.

43 A. Tsamaloukas, H. Szadkowska, P. J. Slotte and H. Heerklotz, Biophys. J., 2005, 89, 1109.

44 C. A. López, A. H. de Vries and S. J. Marrink, Sci. Rep., 2013, 3,1 .

45 S. E. Kwon and E. R. Chapman, Neuron, 2011, 70, 847.

46 S. Y. Jung, J. M. Kim, S. K. Min, O. B. Kim, D. H. Jang, H. K. Kang and B. M. Min, Biomaterials, 2012, 33, 3967. 